\title{
A combination of pocket, double-clip countertraction, and isolated HybridKnife as a quick and safe strategy for colonic endoscopic submucosal dissection
}

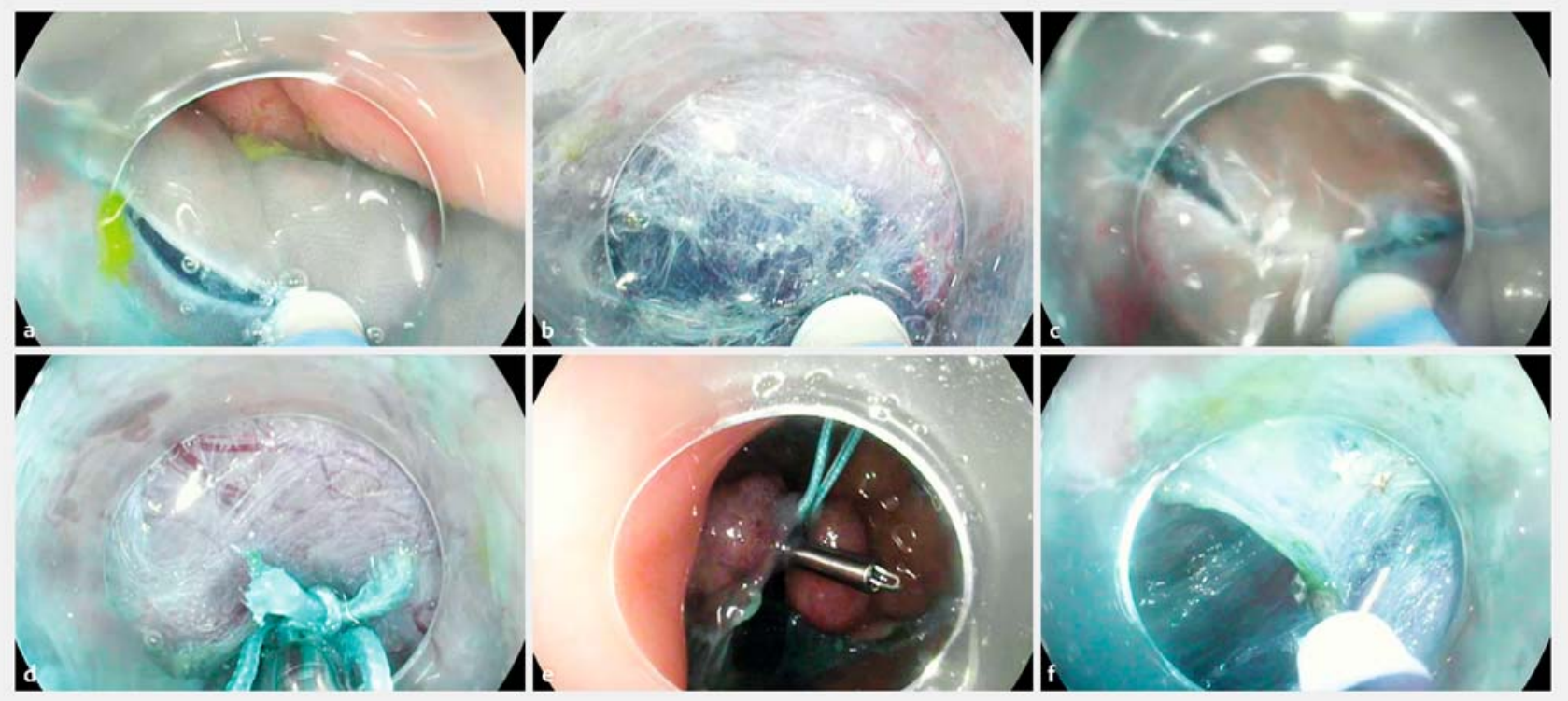

Fig. 1 Endoscopic views showing: a the mucosal incision being made at the proximal part of the lesion; $\mathbf{b}$ the pocket being created; $\mathbf{c}$ the mucosal incision being completed around the lesion; $\mathbf{d}$ attachment of a clip with a small ring of suture thread beneath the lesion; $\mathbf{e}$ countertraction, which is possible thanks to the double-clip technique; $\mathbf{f}$ safe resection of the remnant submucosal fibers thanks to the use of a HybridKnife type O (isolated).

The colon is considered to be one of the most technically challenging locations for endoscopic submucosal dissection (ESD) when superficial neoplastic lesions are being treated [1]. The difficulties include: the colonic loops, intestinal motility, the folded anatomy, problems caused by inconstant gravity, and constant modification of the operative fieldof-view attributable to insufflation. Good exposure of the submucosal layer is key for safe and efficient ESD; this can be particularly challenging in the colon where it is difficult to maintain a tangential position close to the muscle layer. Many tips and tricks have been reported to facilitate colonic ESD, including:

- the use of gravity;

- creation of a pocket [2];

- tunnel dissection;

- clip [3] or double-clip countertraction (ring-thread countertraction [4]);

- the use of a waterjet injection knife [5].
Although individual physicians will prefer certain tips or tricks with which they are familiar, little information is available on combinations of these technical approaches. As case numbers are increasing worldwide, and as colorectal cancer screening programs are becoming more common and effective, further technical improvements are imperative. Here, we report on our treatment strategy for coIonic ESD and seek to facilitate the resection of large superficial colonic lesions.

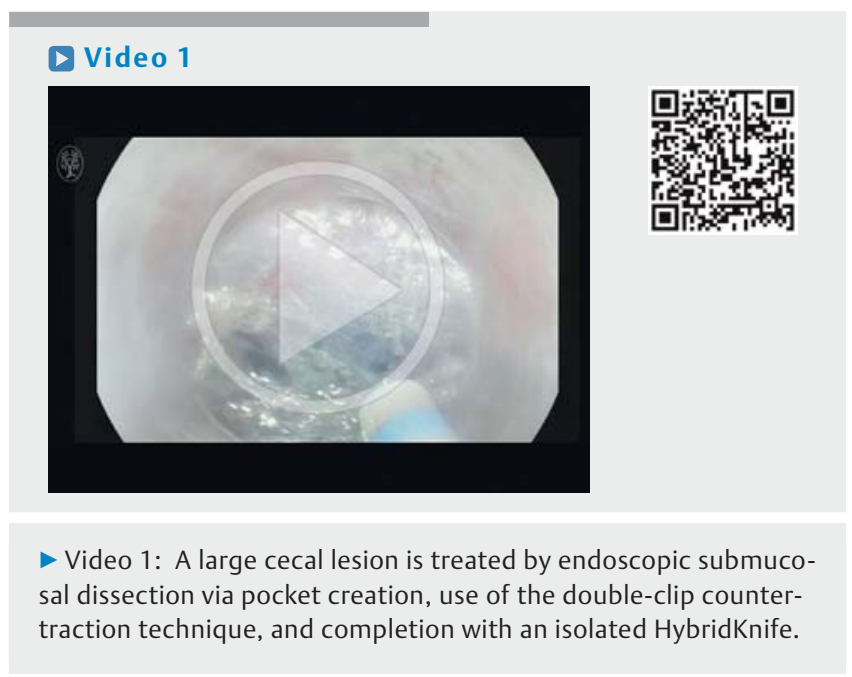


First, we perform a careful diagnostic evaluation using a high-definition endoscope (HQ190, Olympus). We then begin ESD using a dedicated endoscope that allows retroflexion throughout the colon (Pentax Ultraflex; 580 RD, Fujinon). Each procedure commences using a DualKnife to create a mucosal incision at one side of the lesion ( $\mathbf{F i g} \mathbf{1} \mathbf{a}$ ); we then create a pocket under the lesion ( $\mathbf{F i g} \mathbf{1} \mathbf{b}$ ). Further development of a pocket-like tunnel facilitates a perfect view of the submucosal layer, avoiding leakage of submucosal fluid and stabilizing the endoscope beneath the lesion. After a large pocket has been created, we complete the mucosal incision around the lesion ( $\triangleright$ Fig.1 c). The first clip, attached to a small ring of suture thread, is passed through the operative channel and fixed beneath the lesion ( $\mathbf{F i g . 1} \mathbf{d}$ ). The suture thread is then grasped by another clip and attached to the opposite colonic wall. This double-clip technique (also termed ring-thread countertraction) allows the remnant submucosal fibers to be tensioned ( $\triangleright$ Fig. 1 e). Use of a HybridKnife type $\mathrm{O}$ (Erbe Medical, Tübingen, Germany), which has an isolated tip and the capacity to deliver high-pressure injections, allows rapid and safe completion of the procedure with a perfect view of the submucosal space ( $\triangleright$ Fig.1 $\mathbf{f}$; - Video 1).

We use this strategy to efficiently, rapidly, and safely treat most patients who re- quire colonic ESD. We suggest that such a strategy could help to make the use of colonic ESD more widespread and avoid the need for surgery for large colonic superficial neoplasia.

Endoscopy_UCTN_Code_TTT_1AQ_2AD

\section{Competing interests}

Dr Jérémie Jacques: Meetings invitation: Abbvie, Hospira, Norgine; Lectures for Abbvie, Hospira. Dr Romain Legros: Meetings invitation: Abbvie, Boston scientific; Lectures for Hospira. Dr Jérôme Rivory: Meetings invitation: MSD, Abbvie, Norgine, Boston scientific; Lecture: Norgine.

\section{The Authors}

Jérémie Jacques ${ }^{1}$, Romain Legros ${ }^{1}$, Aurélie Charissoux ${ }^{2}$, Jérôme Rivory ${ }^{3}$, Denis Sautereau ${ }^{1}$, Emmanuelle Pauliat ${ }^{4}$, Mathieu Pioche $^{3}$

1 Gastroentérologie et endoscopie digestive, CHU Dupuytren, Limoges, France

2 Anatomopathologie, CHU Dupuytren, Limoges, France

3 Unité d'endoscopie digestive, Service de Gastroentérologie - Pavillon H, Hôpital Edouard Herriot, Lyon, France

4 Pharmacie hospitalière, CHU Dupuytren, Limoges, France
Corresponding author

Jérémie Jacques, MD

Service d'Hépato-gastro-entérologie, $\mathrm{CHU}$

Dupuytren, 87042 Limoges, France

Fax: +33-5-55058733

jeremiejacques@gmail.com

\section{References}

[1] Saunders BP, Tsiamoulos ZP. Endoscopic mucosal resection and endoscopic submucosal dissection of large colonic polyps. Nat Rev Gastroenterol Hepatol 2016; 13: 486 496

[2] Miura Y, Shinozaki S, Hayashi Y et al. Duodenal endoscopic submucosal dissection is feasible using the pocket-creation method. Endoscopy 2017; 49: 8-14

[3] Yamasaki Y, Takeuchi Y, Uedo N et al. Traction-assisted colonic endoscopic submucosal dissection using clip and line: a feasibility study. Endosc Int Open 2016; 4: E51 - E55

[4] Mori H, Kobara H, Nishiyama $\mathrm{N}$ et al. Novel effective and repeatedly available ringthread counter traction for safer colorectal endoscopic submucosal dissection. Surg Endosc 2016: DOI: 10.1007/s00464-0165326-7 [Epub ahead of print]

[5] Huang R, Yan H, Ren G et al. Comparison of O-Type HybridKnife to conventional knife in endoscopic submucosal dissection for gastric mucosal lesions. Medicine (Baltimore) 2016; 95: e3148

\section{Bibliography}

DOI http://dx.doi.org/10.1055/s-0043-104522

Endoscopy 2017; 49: E134-E135

(c) Georg Thieme Verlag KG

Stuttgart · New York

ISSN 0013-726X 